\title{
Evaluation of LDL Subfractions and Lipid Biomarkers in Patients with Gestational Diabetes Mellitus: A Prospective Study
}

Ercan Saruhan ( $\nabla$ ercansaruhan@mu.edu.tr)

Mugla Sitki Kocman Universitesi Tip Fakultesi https://orcid.org/0000-0001-6416-1442

Emre Ispir

Ataturk State Hospital

Yalcin Basaran

Mugla Research and Training Hospital, Mugla

Eren Akbaba

Mugla Sitki Kocman University, Mugla, Turkey

Kursad Tosun

Siena College, Loudonville, NY, USA.

Mutay Aslan

Akdeniz University

\section{Research Article}

Keywords: Betatrophin, diabetes mellitus, lipoprotein, pregnancy, paraoxonase

Posted Date: January 24th, 2022

DOI: https://doi.org/10.21203/rs.3.rs-1252636/v1

License: (9) (i) This work is licensed under a Creative Commons Attribution 4.0 International License. Read Full License 


\section{Abstract}

Purpose: Gestational diabetes that occurs during pregnancy leads to changes in lipid metabolism. It was aimed to determine the levels of LDL subfractions, betatrophin, glycosylphosphatidylinositol-anchored high-density lipoprotein binding protein 1 (GPIHBP1), and paraoxonase activity in patients with gestational diabetes mellitus (GDM), and compare with the healthy pregnant controls.

Methods: This prospective case-control study included 41 women separated into two groups as GDM, and the pregnant controls. Serum levels of betatrophin and GPIHBP1 were measured by ELISA kits. LDL subfraction analysis was performed electrophoretically by using the Lipoprint LDL subfraction kit. Serum paraoxonase activity was determined using photometric paraoxonase assay kit.

Results: Serum betatrophin, and GPIHBP1 levels were found to be significantly higher in patients with GDM compared to the pregnant controls $(p<0.001)$. Higher levels of LDL6 subfraction and smaller mean LDL size was also found in GDM patients. No significant difference was found in PON1 activity.

Conclusion: Betatrophin, and GPIHBP1 may have a role in the pathogenesis of gestational diabetes mellitus. These biomarkers should be assessed in the postpartum period with long-term clinical outcomes such as atherosclerosis and cardiovascular diseases.

\section{Introduction}

Gestational diabetes mellitus (GDM) is defined as glucose intolerance that is first diagnosed during pregnancy. GDM is the most prevalent metabolic disorder during pregnancy and is present in $8 \%$ of all pregnancies [1]. Although most patients with GDM return to normal glucose tolerance in the postpartum period, there remains a higher risk of developing diabetes mellitus in later life. Higher glucose levels in pregnancy can cause complications such as macrosomia, birth trauma, hypoglycemia, and intrauterine fetal death [2]. By causing insulin resistance and lipid metabolism changes, GDM also increases the risk of cardiovascular disease [3].

In recent studies, biomarkers associated with lipid metabolism disorders have been investigated and their relationship with insulin resistance evaluated. Betatrophin, also known as lipasin, RIFL (refeeding-induced fat and liver), and angiopoietin-like protein 8 (ANGPTL8), is one of these biomarkers produced in liver and adipose tissue [4]. Betatrophin levels increase with insulin secretion in the postprandial period and decrease the lipoprotein lipase activity of adipose tissue [5]. Ren et al. showed that RIFL-null mice have increased lipoprotein lipase activity and low plasma triglyceride levels [6]. Ebert et al. and Erol et al. found higher serum betatrophin levels in GDM patients compared to healthy pregnant control subjects [7, 8]. In a study by Huang et al. of 49 pregnant and 31 non-pregnant women, it was shown that betatrophin levels were higher in pregnant women, regardless of glucose tolerance [9].

Another lipid biomarker, Glycosyl-phosphatidyl-inositol-anchored high-density lipoprotein-binding protein 1 (GPIHBP1) is synthesized from endothelial cells and increases lipolytic activity by binding to lipoprotein 
lipase enzyme [10]. GPIHBP1 knock-out mice have been shown to have high plasma concentrations of chylomicrons with triglyceride levels up to $5000 \mathrm{mg} / \mathrm{dL}$ [11].

Paraoxonase-1 (PON1) is an enzyme in HDL cholesterol, which prevents lipoprotein oxidation by hydrolyzing lipid peroxides and oxidized LDL [12]. In diabetic patients, the protective effect of the PON1 enzyme against lipid peroxidation has been found to be decreased, and serum PON1 levels have been shown to be decreased in patients with diabetes mellitus compared to a healthy control group $[13,14]$.

Lipoproteins are complex particles, consisting of lipids and proteins that differ from each other in particle size, lipid composition, and density. Lipoproteins are determined by analytical methods such as ultracentrifugation, nuclear magnetic resonance, and polyacrylamide gel electrophoresis (Lipoprint system) [15]. Low-density lipoprotein (LDL) is separated into seven subfractions with Lipoprint System. LDL-1 is the largest lipoprotein and LDL-7 is the smallest. Genetic and environmental factors can influence the profiles of LDL subfractions [16]. Pattern $A$ is characterized by a predominance of the larger, buoyant, LDL-1, and LDL-2 subfractions. Pattern B profile consists of primarily small and dense, LDL-3 to LDL-7 subfractions [17]. Austin et al. showed a 3-fold increased risk of myocardial infarction in patients with pattern B [18]. Qiu et al. compared GDM patients and healthy pregnant women and showed that the risk of developing GDM in patients with pattern B was 4.9-fold higher, and the mean LDL particle size in GDM patients was smaller than that of the control subjects [19]. In a study by Rizzo et al., the mean LDL size in GDM patients was observed to be smaller than in the control group because of decreased LDL-1, and increased LDL-4 subfractions [20].

Gestational diabetes mellitus leads to changes in lipid metabolism and as a result insulin resistance increases in pregnants. Serum levels of betatrophin and small LDL subfractions have previously been studied in patients with GDM, and found increased levels $[7,19]$. However, the underlying mechanisms remain unclear. In addition, the relationship of the disease with lipid biomarkers such as GPIHBP1 and PON1 has not been investigated to date. The aim of this study was to determine the levels of betatrophin, GPIHBP1, PON1, and LDL subfractions in the pregnant controls and patients with GDM to reveal the relationship between these biomarkers and their effects on the pathogenesis of the disease. The most important features distinguishing this study from previous researches were the comparisons of GDM patients with the pregnant controls and that evaluations were made of the additional lipid metabolism biomarker of GPIHBP1, PON1, and LDL subfractions.

\section{Materials And Methods}

\section{Study design}

This prospective case-control study was designed to investigate lipid metabolism in patients with GDM. The study included 41 women, who were separated into two groups. Patients with gestational diabetes mellitus (GDM, $n=21$ ) were diagnosed from a 75-gram oral glucose tolerance test (OGTT) between 24 and 28 gestational weeks according to the International Association of Diabetes and Pregnancy Study 
Group (IADPSG) diagnostic criteria [21]. All the patients were newly diagnosed during pregnancy and were disease-free before pregnancy. The control group consisted of age and body mass index (BMI) matched pregnant $(n=20)$ women.

Patients were excluded from the study if they had a multiple pregnancy, were morbidly obese (BMI > 35), had a pre-pregnancy diagnosis of diabetes mellitus, hyperlipidemia, or thyroid dysfunction, or were aged > 40 years or $<18$ years. Demographic information was obtained from the patient medical records.

This study was reviewed and approved by Clinical Research Ethical Board of Muğla Sıtkı Koçman University (31/05/2018-08/II). This study was conducted under the ethical standards laid down in the 1964 Declaration of Helsinki and its later amendments. All participants gave informed consent before their inclusion in the study.

\section{Measurement of routine biochemical parameters}

Fasting blood samples were collected into gel-separated blood tubes, which were then centrifuged at $2000 \times \mathrm{g}$ for 10 minutes. Glucose, cholesterol, triglycerides, HDL cholesterol (HDL-C), TSH, and insulin concentrations were measured using a Roche Cobas 8000 automatic biochemical analyzer with commercial reagents (Roche Diagnostics GmbH; Mannheim, Germany). LDL cholesterol (LDL-C) and VLDL cholesterol (VLDL-C) were calculated using the Friedewald formula [22]. Insulin resistance was estimated with HOMA-IR ((insulin $(\mu \mathrm{U} / \mathrm{mL}) \times$ glucose $(\mathrm{mg} / \mathrm{dL})) / 405)$ [23]. The remaining serum samples were aliquoted and stored at $-80^{\circ} \mathrm{C}$ until analysis of betatrophin, GPIHBP1, PON1, and LDL subfractions.

\section{Measurement of serum betatrophin and GPIHBP1 concentrations}

Serum betatrophin and GPIHBP1 concentrations were determined using a human betatrophin enzymelinked immunosorbent assay (ELISA) kit (Bioassay Technology Laboratory, Shangai, China; Cat No: E3381Hu) and a human GPIHBP1 ELISA kit (Bioassay Technology Laboratory, Shangai, China; Cat No: $\mathrm{E} 6678 \mathrm{Hu}$ ) according to the instructions of the manufacturer. All measurements were performed in duplicate using a microplate reader (Multiskan GO; Thermo Scientific, Rockford, IL, USA). GPIHBP1 assay sensitivity was $0.29 \mathrm{ng} / \mathrm{mL}$ with inter-assay and intra-assay coefficients of variation $<10 \%$ and $<8 \%$, respectively. Betatrophin assay sensitivity was $0.23 \mathrm{ng} / \mathrm{mL}$ with inter-assay and intra-assay coefficients of variation $<10 \%$ and $<8 \%$, respectively.

\section{Measurement of serum paraoxonase activity}

Serum paraoxonase activity was determined using the paraoxonase assay kit (Rel Assay Diagnostics, Gaziantep, Turkey). Paraoxon was used as a substrate and the rate of hydrolysis was measured at 412 $\mathrm{nm}$. Paraoxonase activity was calculated from the molar absorption coefficient of $18.290 \mathrm{M}$ and expressed as U/L.

\section{LDL subfraction analysis}


LDL subfraction analysis was performed electrophoretically by using the Lipoprint LDL subfraction kit, which is a linear polyacrylamide gel electrophoresis system (Quantimetrix, Redondo Beach, CA, USA) [15]. First, $25 \mu \mathrm{l}$ of serum sample and $200 \mu \mathrm{l}$ of loading gel solution were added to the polyacrylamide gel tubes. This mixture was photopolymerized for 30 minutes at room temperature. A total of 12 lipoprotein subfractions were separated electrophoretically in the serum samples and control solution (Liposure Serum Lipoprotein Control, Quantimetrix Corp., CA, USA) at a constant of $3 \mathrm{~mA} /$ tube for $1 \mathrm{~h}$. After separation, one VLDL, 3 intermediate bands (Midbands C, B, and A), 7 LDL subfractions (LDL1-LDL7), and $1 \mathrm{HDL}$ band appeared. After electrophoresis, the gel tubes were scanned and the percentages of the area under the curve (AUC\%) of each lipoprotein subfraction, as well as the mean LDL size (Angstrom, $\AA$ ) were calculated with Lipoware software (Quantimetrix Corp., CA, USA). The AUC\% for each lipoprotein band was multiplied by cholesterol concentration to determine the amount of cholesterol for each band in $\mathrm{mg} / \mathrm{dL}$. LDL cholesterol was calculated as the total of the cholesterol concentrations of all LDL subfractions (LDL1-LDL7) and Midbands (A-C). The lipoprotein profile containing predominantly LDL-1 and LDL-2 subfractions (LDL size $\geq 255 \AA$ ) was described as "Pattern A", and the profile containing LDL-3 to LDL-7 subfractions (small and dense particles, LDL size $<255 \AA$ ) was described as "Pattern B" [18].

\section{Statistical analysis}

In this study, we used the rank-sum procedure to investigate whether there is a difference between the GDM patients and healthy pregnant controls in terms of the biochemical parameters. The purpose behind using ranks was that the distributions of the data were skewed with a large spread, and the sample sizes were moderately large. This procedure relies on a transformation that replaces each observation by its rank in the combined sample. Particularly, we used the Wilcoxon Rank-Sum Test with Continuity Correction to test the null hypothesis of identical population distributions from two independent samples, namely the GDM and control group. The summary statistics are given as minimum, maximum, and median values. In addition, we estimated the differences in biochemical parameters between the populations of the GDM patients and control group using $95 \%$ confidence intervals. To compare the LDL5, LDL6, and LDL7 values, the rank-sum test was inadequate because of the large number of ties. Since, the permutation test requires no distributional assumptions or special conditions, we used the permutation test for calculating the $p$-values for these parameters. A p-value of less than 0.05 was considered statistically significant. All computational analysis was performed using $\mathrm{R}$ software (version 4.0.2, R Core Team, 2016).

\section{Results}

A total of 41 women were included in this study. The median age of GDM patients was 29 (range 20-36 years), and the median age of the control group was also 29 (range 20-38 years). There was no statistically significant difference between the groups in terms of age and BMI. The demographic data and biochemical parameters of the participants were summarized in Table 1. 
Table 1

Demographic data and biochemical parameters of GDM patients and Control group.

\begin{tabular}{|c|c|c|c|c|c|}
\hline & $\begin{array}{l}\text { GDM Patients } \\
(n=21)\end{array}$ & $\begin{array}{l}\text { Controls } \\
(n=20)\end{array}$ & $\begin{array}{l}\text { Estimated } \\
\text { Difference }\end{array}$ & $\begin{array}{l}95 \% \mathrm{Cl} \text { for } \\
\text { Difference }\end{array}$ & $\begin{array}{l}\text { p- } \\
\text { value }\end{array}$ \\
\hline & $\begin{array}{l}\text { Median (Min, } \\
\text { Max) }\end{array}$ & $\begin{array}{l}\text { Median (Min, } \\
\text { Max) }\end{array}$ & & & \\
\hline Age (years) & $29(20,36)$ & $29(20,38)$ & & & 0.834 \\
\hline $\begin{array}{l}\text { Glucose } \\
\text { (mg/dL) }\end{array}$ & $90(73,150)$ & $86(63,109)$ & & & 0.245 \\
\hline $\begin{array}{l}\text { Insulin } \\
(\mu \mathrm{IU} / \mathrm{mL})\end{array}$ & $12.5(5.7,117)$ & $9.4(4.2,16.4)$ & 3.1 & $0.5-6.8$ & 0.020 \\
\hline HOMA-IR & $\begin{array}{l}2.73(1.02, \\
43.33)\end{array}$ & $\begin{array}{l}1.91(0.86 \\
3.52)\end{array}$ & 0.87 & $0.04-1.85$ & 0.037 \\
\hline $\mathrm{TSH}(\mu \mathrm{U} / \mathrm{mL})$ & $\begin{array}{l}1.71(0.96 \\
2.52)\end{array}$ & $\begin{array}{l}1.75(0.9 \\
2.48)\end{array}$ & & & 0.814 \\
\hline $\begin{array}{l}\text { Triglyceride } \\
\text { (mg/dL) }\end{array}$ & $205(60,392)$ & $172(41,302)$ & & & 0.279 \\
\hline $\begin{array}{l}\text { Cholesterol } \\
\text { (mg/dL) }\end{array}$ & $251(152,419)$ & $\begin{array}{l}253.5(142, \\
335)\end{array}$ & & & 0.506 \\
\hline LDL-C (mg/dL) & $\begin{array}{l}135.4(51.5, \\
283)\end{array}$ & $\begin{array}{l}116.2(53, \\
243.8)\end{array}$ & & & 0.386 \\
\hline $\begin{array}{l}\text { VLDL-C } \\
(\mathrm{mg} / \mathrm{dL})\end{array}$ & $41(12,78.4)$ & $\begin{array}{l}34.4(8.2 \\
60.4)\end{array}$ & & & 0.279 \\
\hline HDL-C (mg/dL) & $\begin{array}{l}73.7(31.3, \\
97.4)\end{array}$ & $\begin{array}{l}66.4(53.1, \\
98.8)\end{array}$ & & & 0.908 \\
\hline $\begin{array}{l}\text { Betatrophin } \\
(\mathrm{ng} / \mathrm{mL})\end{array}$ & $\begin{array}{l}4.39(1.56 \\
64.87)\end{array}$ & $\begin{array}{l}1.73(1.21, \\
65.22)\end{array}$ & 2.2 & $0.19-6.82$ & 0.010 \\
\hline $\begin{array}{l}\text { GPIHBP1 } \\
(\mathrm{ng} / \mathrm{mL})\end{array}$ & $\begin{array}{l}4.19(1.05 \\
78.12)\end{array}$ & $\begin{array}{l}1.56(0.66 \\
77)\end{array}$ & 1.76 & $0.18-8.58$ & 0.016 \\
\hline PON1 (U/L) & $330(82,1297)$ & $\begin{array}{l}273.5(115 \\
1321)\end{array}$ & & & 0.847 \\
\hline $\begin{array}{l}\text { Summary statist } \\
\text { the Wilcoxon Ra } \\
\text { significant differ }\end{array}$ & $\begin{array}{l}\text { s are given as m } \\
\text {-Sum Test with } \\
\text { ce between gro }\end{array}$ & $\begin{array}{l}\text { an and (minimu } \\
\text { tinuity Correctic }\end{array}$ & $\begin{array}{l}\text {, maximum) } \\
\text { A bold p-val }\end{array}$ & $\begin{array}{l}\text { values were o } \\
\text { cates a statist }\end{array}$ & d from \\
\hline $\begin{array}{l}\text { Abbreviations: H } \\
\text { stimulating horm } \\
\text { cholesterol; VLD } \\
\text { anchored high d }\end{array}$ & $\begin{array}{l}\text { MA-IR, homeos t } \\
\text { ne; HDL-C, high- } \\
\text { C, very low-dens } \\
\text { sity lipoprotein }\end{array}$ & $\begin{array}{l}\text { model assess } \\
\text { sity lipoprotein } \\
\text { poprotein chole } \\
\text { ing protein } 1 ; P\end{array}$ & $\begin{array}{l}\text { ent of insulin } \\
\text { olesterol; LD } \\
\text { erol; GPIHBP } \\
\text { V1, paraoxon }\end{array}$ & $\begin{array}{l}\text { nce; TSH, thy } \\
\text { I-density lipof } \\
\text { ssylphosphati }\end{array}$ & sitol- \\
\hline
\end{tabular}

These data provided convincing evidence that GDM patients had higher levels of GPIHBP1 and Betatrophin than the control group (respectively, one-sided $p$-value $=0.016,0.010$, Wilcoxon rank sum test 
with continuity correction). These small p-values indicated that it was highly unlikely that the observed results were due to chance alone. Therefore, there were statistically significant differences between two populations. An estimated value for the difference in GPIHBP1 was $1.76 \mathrm{ng} / \mathrm{mL}$ with a $95 \%$ confidence interval of $0.18 \mathrm{ng} / \mathrm{mL}$ to $8.58 \mathrm{ng} / \mathrm{mL}$. That was, with $95 \%$ confidence the difference in GPIHBP1 levels between GDM patients and the control group was between $0.18 \mathrm{ng} / \mathrm{mL}$ and $8.58 \mathrm{ng} / \mathrm{mL}$. The estimated difference in Betatrophin levels was $2.20 \mathrm{ng} / \mathrm{mL}$ with the $95 \%$ confidence interval of $0.19 \mathrm{ng} / \mathrm{mL}$ to 6.82 $\mathrm{ng} / \mathrm{mL}$.

As expected, insulin and HOMA-IR levels were significantly higher in the GDM patients (respectively, onesided $p$-value $=0.037,0.020$, Wilcoxon rank sum test with continuity correction). However, there was no sufficient evidence that PON1, TSH, triglyceride, cholesterol, LDL-C, VLDL-C, and HDL-C levels differ in GDM patients from the control group (Table 1, all p-values $>0.05$ ).

We also looked into the differences in LDL subfractions. The statistical analysis showed that the LDL6 levels and the mean LDL size were significantly different in two populations (respectively, p-values = $0.036,0.004)$. These data provided no evidence that the other LDL subfractions of GDM patients and the control group were different (Table 2, all p-values > 0.05). 
Table 2

LDL subfraction analysis of GDM patients and Control group.

\begin{tabular}{|c|c|c|c|}
\hline & GDM Patients $(n=21)$ & Controls $(n=20)$ & p-value \\
\hline & Median (Min, Max) & Median (Min, Max & \\
\hline VLDL (mg/dL) & $30(19,62)$ & $33.5(11,47)$ & 0.666 \\
\hline IDLC (mg/dL) & $23(10,40)$ & $21.5(6,36)$ & 0.714 \\
\hline IDLB (mg/dL) & $17(10,34)$ & $18(11,31)$ & 0.637 \\
\hline IDLA (mg/dL) & $11(4,25)$ & $10.5(3,25)$ & 0.478 \\
\hline LDL1 (mg/dL) & $25(11,50)$ & $20.5(9,34)$ & 0.539 \\
\hline LDL2 (mg/dL) & $38(9,68)$ & $33(21,60)$ & 0.611 \\
\hline LDL3 (mg/dL) & $27(5,57)$ & $23.5(12,40)$ & 0.990 \\
\hline LDL4 (mg/dL) & $12(0,51)$ & $7.5(2,35)$ & 0.327 \\
\hline LDL5 (mg/dL) & $2(0,22)$ & $1(0,19)$ & $0.145^{\dagger}$ \\
\hline LDL6 (mg/dL) & $0(0,8)$ & $0(0,4)$ & $0.036^{\dagger}$ \\
\hline LDL7 (mg/dL) & $0(0,36)$ & $0(0,1)$ & $0.232^{\dagger}$ \\
\hline $\mathrm{HDL}(\mathrm{mg} / \mathrm{dL})$ & $59(23,75)$ & $54.5(35,86)$ & 0.620 \\
\hline Mean LDL size $(\AA)$ & $298(266,329)$ & $276.5(264,305)$ & 0.004 \\
\hline $\begin{array}{l}\text { Summary statistics } \\
\text { the Wilcoxon Rank- } \\
\text { indicates a statistic }\end{array}$ & $\begin{array}{l}n \text { as median and (minin } \\
\text { t with Continuity Correc } \\
\text { ificant difference betwe }\end{array}$ & $\begin{array}{l}\text { ximum). The p-valu } \\
{ }^{+} \text {the permutation te } \\
\text { s. }\end{array}$ & $\begin{array}{l}\text { tained fro } \\
p \text {-value }\end{array}$ \\
\hline $\begin{array}{l}\text { Abbreviations: VLD } \\
\text { density lipoprotein; }\end{array}$ & $\begin{array}{l}\text { N-density lipoprotein; II } \\
\text { ר-density lipoprotein }\end{array}$ & diate-density lipc & low- \\
\hline
\end{tabular}

\section{Discussion}

Gestational diabetes mellitus is a clinical condition of impaired glucose tolerance that begins or is first determined during pregnancy. Betatrophin, a recent biomarker, has been shown to play a role in lipid and glucose metabolism $[24,25]$. Studies that have aimed to determine the role of betatrophin in the pathophysiology of GDM, have mainly focused on the glucose metabolism parameters, and its effect on impaired lipid metabolism has not been shown.

In this study, LDL subfractions and biomarkers of lipid metabolism were evaluated in patients with GDM. The main finding of the study was the presence of higher betatrophin, and GPIHBP1 levels in patients with GDM. LDL subfraction analysis also showed higher levels of small dense subfraction LDL-6 and lower mean LDL size in patients. 
The serum levels of betatrophin and GPIHBP1 were found to be significantly higher in the GDM group compared to the pregnant control group in the current study. These results indicate that these markers could be a part of the adaptive mechanism of lipid metabolism against insulin resistance. In previous studies, betatrophin levels have also been found to be higher in patients with GDM [7-9]. Those studies revealed betatrophin as a risk factor for GDM, and the finding of higher levels of betatrophin in GDM patients in the current study is consistent with those results. Fenzl et al. conducted a study of type 1 diabetic patients and found a correlation between betatrophin and LDL cholesterol levels [26]. However, no correlation between the levels of betatrophin and LDL cholesterol was determined in the current study.

To the best of our knowledge, this is the first study to have compared GPIHBP1 levels in gestational diabetes mellitus. We found higher levels of GPIHBP1 in GDM patients. These findings suggest that GPIHBP1, which plays an important role in the lipolysis of chylomicrons by binding to lipoprotein lipase enzyme, increases in response to insulin resistance [10].

The activity of PON1 enzyme, which is an antioxidant enzyme associated with HDL, was also investigated in this study, and no significant difference was found between the groups. Although there are no studies about gestational metabolic diseases, some studies have reported a decrease in serum PON1 activity, especially in patients with diabetes mellitus compared to a non-diabetic group $[13,14]$.

In the evaluation of the LDL subfractions in a study by Qiu et al, pattern B was found to be associated with a 4.9-fold increased risk of developing GDM, and the mean LDL particle size was smaller in GDM patients compared to the control group [19]. In a study by Rizzo et al., the mean LDL size in patients with GDM was determined to be smaller than that of the control group due to decreased LDL-1, and increased LDL-4 subfractions [20]. Sattar et al. reported higher triglycerides levels and a change in the LDL profile towards smaller and denser subfractions in line with the current study findings [27]. Consistent with the studies mentioned above, higher levels of LDL6 subfraction and smaller mean LDL size was found in GDM patients compared to the pregnant control group in our study.

This study has some limitations to be acknowledged. First, the dietary habits of the participants were not controlled and standardized in the study. The second limitation was the small sample size of groups. Further studies with larger numbers of patients are required. Despite these limitations, this study can be considered of value with regard to determining differences in betatrophin, GPIHBP1, and LDL subfraction levels between patients and control subjects.

In conclusion, the results of this study demonstrated that betatrophin, and GPIHBP1 levels increased in GDM. LDL subfractions analysis showed that this increase was mostly due to the smaller and denser LDL subfraction (LDL6) in GDM patients. Betatrophin and GPIHBP1 are adaptive mechanisms in response to insulin resistance, and the study results suggest that betatrophin and GPIHBP1 could be potential biomarkers of metabolic syndrome in patients with GDM. There is a need for further prospective studies with larger samples to fully elucidate the mechanisms of insulin resistance in pregnancy. These biomarkers should be assessed in the postpartum period with long-term clinical outcomes such as atherosclerosis and cardiovascular diseases. 


\section{Declarations}

\section{Authors' Contribution}

E Saruhan: Project development, Data collection, Manuscript writing

E Ispir: Project development, Manuscript editing

Y Basaran: Data collection, Manuscript editing

E Akbaba: Data collection, Manuscript editing

K Tosun: Data analysis, Manuscript editing

M Aslan: Project development, Data collection, Manuscript editing

\section{Funding}

This study was granted by the Muğla Sıtkı Koçman University Research Projects Coordination Offıce through Project Grant Number: (19/086/02/3/4).

\section{Competing interests}

The authors declare that they have no known competing financial interests or personal relationships that could have appeared to influence the work reported in this paper.

\section{Author Contributions}

Ercan Saruhan: conceptualization, methodology, funding acquisition, formal analysis, investigation, writing - original draft, project administration. Emre Ispir: investigation, resources, writing - review and editing. Yalcin Basaran: writing - review and editing, data curation. Eren Akbaba: writing - review and editing, data curation. Kursad Tosun: writing - review and editing, data curation. Mutay Aslan: supervision, methodology, editing, writing - review and editing

\section{Ethics approval}

This study was reviewed and approved by Clinical Research Ethical Board of Muğla Sıtkı Koçman University (31/05/2018-08/II). This study was conducted under the ethical standards laid down in the 1964 Declaration of Helsinki and its later amendments. 


\section{Consent to participate}

All participants gave informed consent before their inclusion in the study.

\section{Consent to publish}

Patients signed informed consent regarding publishing their data.

\section{References}

1. Jiwani A, Marseille E, Lohse N, Damm P, Hod M, Kahn JG (Jun 2012) "Gestational diabetes mellitus: results from a survey of country prevalence and practices,". J Matern Fetal Neonatal Med 25(6):600610. doi: $10.3109 / 14767058.2011 .587921$

2. Page KA, Romero A, Buchanan TA, Xiang AH (Apr 2014) "Gestational diabetes mellitus, maternal obesity, and adiposity in offspring,". J Pediatr 164(4):807-810. doi: 10.1016/j.jpeds.2013.11.063

3. Chen Y et al (May 19 2016) "Changes in profile of lipids and adipokines in patients with newly diagnosed hypothyroidism and hyperthyroidism,". Sci Rep 6:26174. doi: 10.1038/srep26174

4. Kong F-J, Ma L-L, Li G, Chen Y-X, Zhou J-Q (2017) "Circulating Betatrophin Levels and Gestational Diabetes Mellitus: A Systematic Review and Meta-Analysis,". PLoS ONE 12(1):e0169941. doi: 10.1371/journal.pone.0169941

5. Sanchis-Gomar F, Perez-Quilis C (2014) "The p38-PGC-1alpha-irisin-betatrophin axis: Exploring new pathways in insulin resistance," Adipocyte, vol. 3, no. 1, pp. 67-8, Jan 1 doi: 10.4161/adip.27370

6. Ren G, Kim JY, Smas CM (2012) "Identification of RIFL, a novel adipocyte-enriched insulin target gene with a role in lipid metabolism," (in eng), American journal of physiology. Endocrinology and metabolism, vol. 303, no. 3, pp. E334-E351, doi: 10.1152/ajpendo.00084.2012

7. Ebert T et al (Jul 2015) "Betatrophin levels are increased in women with gestational diabetes mellitus compared to healthy pregnant controls,". Eur J Endocrinol 173(1):1-7. doi: 10.1530/EJE-14-0815

8. Erol O, Ellidag HY, Ayik H, Ozel MK, Derbent AU, Yilmaz N (2015) Evaluation of circulating betatrophin levels in gestational diabetes mellitus," (in English). Gynecol Endocrinol 31(8):652-656. doi: 10.3109/09513590.2015.1056142

9. Huang Y, Fang C, Ma Z, Guo H, Wang R, Hu J (Jun 2016) "Betatrophin Levels were Increased in Pregnant Women with or without Gestational Diabetes Mellitus and Associated with Beta Cell Function,". Rev Bras Ginecol Obstet 38(6):287-292. doi: 10.1055/s-0036-1584566

10. Young SG et al (2019) "GPIHBP1 and Lipoprotein Lipase, Partners in Plasma Triglyceride Metabolism," (in eng), Cell Metab, vol. 30, no. 1, pp. 51-65, Jul 2 doi: 10.1016/j.cmet.2019.05.023

11. Beigneux AP et al (Apr 2007) "Glycosylphosphatidylinositol-anchored high-density lipoproteinbinding protein 1 plays a critical role in the lipolytic processing of chylomicrons,". Cell Metab 5(4):279-291. doi: 10.1016/j.cmet.2007.02.002 
12. Khalil A, Fulop T, Berrougui H (Jan 20 2021) "Role of Paraoxonase1 in the Regulation of High-Density Lipoprotein Functionality and in Cardiovascular Protection," (in eng). Antioxid Redox Signal 34(3):191-200. doi: 10.1089/ars.2019.7998

13. Flekac M, Skrha J, Zidkova K, Lacinova Z, Hilgertova J (2008) "Paraoxonase 1 gene polymorphisms and enzyme activities in diabetes mellitus,". Physiol Res 57(5):717-726.

https://www.ncbi.nlm.nih.gov/pubmed/17949258

14. Karabina S-AP, Lehner AN, Frank E, Parthasarathy S, Santanam N (2005) "Oxidative inactivation of paraoxonase-implications in diabetes mellitus and atherosclerosis," (in eng), Biochim Biophys Acta, vol. 1725 , no. 2 , pp. 213-221,

$109 / /$

2005, doi: 10.1016/j.bbagen.2005.07.005

15. Hoefner DM et al (2001) "Development of a rapid, quantitative method for LDL subfractionation with use of the Quantimetrix Lipoprint LDL System," (in eng), Clin Chem, vol. 47, no. 2, pp. 266-74, Feb https://www.ncbi.nlm.nih.gov/pubmed/11159775

16. McNamara JR, Campos H, Ordovas JM, Peterson J, Wilson PW, Schaefer EJ (1987) "Effect of gender, age, and lipid status on low density lipoprotein subfraction distribution. Results from the Framingham Offspring Study," (in eng), Arteriosclerosis, vol. 7, no. 5, pp. 483-90, Sep-Oct doi: 10.1161/01.atv.7.5.483

17. Coresh J, Kwiterovich PO Jr, Smith HH, Bachorik PS (Oct 1993) Association of plasma triglyceride concentration and LDL particle diameter, density, and chemical composition with premature coronary artery disease in men and women," (in eng). J Lipid Res 34(10):1687-1697

18. Austin MA, Hokanson JE, Brunzell JD (Dec 1994) Characterization of low-density lipoprotein subclasses: methodologic approaches and clinical relevance," (in eng). Curr Opin Lipidol 5(6):395403. doi: $10.1097 / 00041433-199412000-00002$

19. Qiu C, Rudra C, Austin MA, Williams MA (2007) Association of gestational diabetes mellitus and lowdensity lipoprotein (LDL) particle size,. Physiol Res 56(5):571-578.

https://www.ncbi.nlm.nih.gov/pubmed/17223732

20. Rizzo M et al (Dec 2008) "Atherogenic lipoprotein phenotype and LDL size and subclasses in women with gestational diabetes,". Diabet Med 25(12):1406-1411. doi: 10.1111/j.1464-5491.2008.02613.x

21. Association of DI et al (2010) "International association of diabetes and pregnancy study groups recommendations on the diagnosis and classification of hyperglycemia in pregnancy," (in eng), Diabetes Care, vol. 33, no. 3, pp. 676-82, doi: 10.2337/dc09-1848

22. Friedewald WT, Levy RI, Fredrickson DS (Jun 1972) Estimation of the concentration of low-density lipoprotein cholesterol in plasma, without use of the preparative ultracentrifuge," (in eng). Clin Chem 18(6):499-502

23. Matthews DR, Hosker JP, Rudenski AS, Naylor BA, Treacher DF, Turner RC (1985) "Homeostasis model assessment: insulin resistance and beta-cell function from fasting plasma glucose and 
insulin concentrations in man," (in eng), Diabetologia, vol. 28, no. 7, pp. 412-9, Jul doi: $10.1007 /$ bf00280883

24. Quagliarini F et al (2012) "Atypical angiopoietin-like protein that regulates ANGPTL3," (in eng), Proc Natl Acad Sci U S A, vol. 109, no. 48, pp. 19751-6, Nov 27 doi: 10.1073/pnas.1217552109

25. Yi P, Park J-S, Melton DA (2013) "Betatrophin: a hormone that controls pancreatic $\beta$ cell proliferation," (in eng), Cell, vol. 153, no. 4, pp. 747-758, doi: 10.1016/j.cell.2013.04.008

26. Fenzl A et al (2014) "Circulating betatrophin correlates with atherogenic lipid profiles but not with glucose and insulin levels in insulin-resistant individuals," Diabetologia, vol. 57, no. 6, pp. 1204-1208, /06/01 2014, doi: 10.1007/s00125-014-3208-x

27. Sattar N et al (1997) "Lipoprotein Subfraction Changes in Normal Pregnancy: Threshold Effect of Plasma Triglyceride on Appearance of Small, Dense Low Density Lipoprotein1,". The Journal of Clinical Endocrinology \& Metabolism 82(8):2483-2491. doi: 10.1210/jcem.82.8.4126

\section{Figures}

GPIHBP1 (ng/mL)

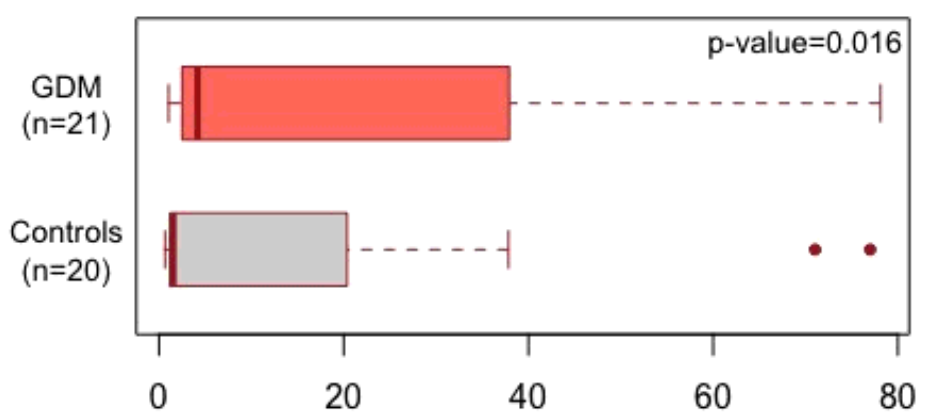

Betatrophin (ng/mL)

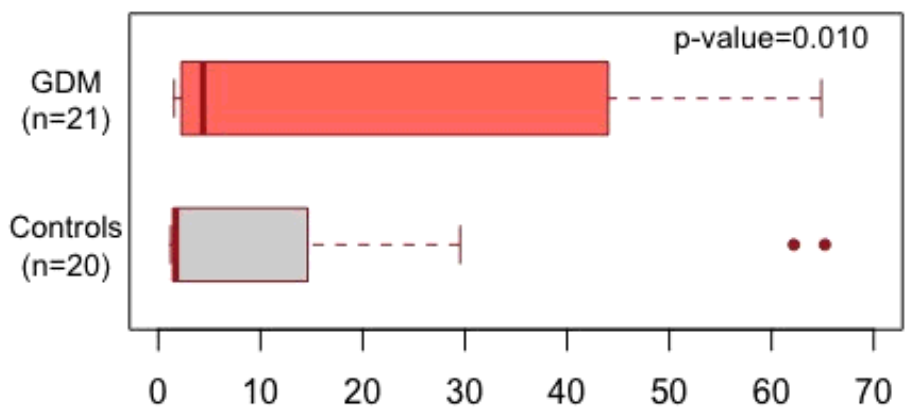

Figure 1

Boxplot of the GPIHBP1 and betatrophin values of the GDM patients and control group. 